\title{
In Remembrance of V. S. Letokhov ${ }^{1}$
}

\author{
C. Bradley Moore \\ Department of Chemistry, University of California, Berkeley, CA 94720-1460, USA \\ e-mail: moorecb@berkeley.edu \\ Received April 17, 2009; published online July 2, 2009
}

DOI: $10.1134 / \mathrm{S} 1054660 X 09170149$

Dear colleagues, friends and readers:

In Vladilen S. Letokhov, we have lost a great scientist, colleague, friend and human being. Thanks to his originality, deep insight, analytical mind, and courage in opening new directions, we have much new science to remember him by and more than a few tantalizing suggestions to inspire our future work.

Vladik and Brad were drawn together in the early 1970 s by a mutual interest in using lasers for isotope separation. We met during Vladik's first visit to Berkeley late in 1973. At that time, he was doing selective, step-wise ionization of atoms for isotope separation. He was also talking about his concept for separating nuclear isomers and collecting them into a geometry that would yield a beam of stimulated gamma-ray emission. Within a few months we had started on our joint papers giving an overview of laser separation of isotopes that were published two or three years later in the Soviet Journal of Quantum Electronics and in Chemical and Biochemical Applications of Lasers. This was heroic work for Vladik as he wrote his half of the English versions and the entirety of both Russian versions, well over 200 pages in each language.

It was always exciting and pleasurable to be with Vladik; his enthusiasm for life and for science was completely infectious. There was a constant stream of ideas for experiments over an incredibly wide range of fields as well as a constant flow of recent results. All of this made for many animated discussions. Visits to each other's labs, institutes, cities and homes are among the great highlights of our own lives. Vladik also shared his best coworkers with us for visits from a few days to many months. We learned about science, education, culture, the Soviet system and the Russian character. We began to understand the darkness of great Russian novels and the moods of Russian symphony composers. We developed a fondness for caviar

\footnotetext{
${ }^{1}$ The article is published in the original.
}

and smoked sturgeon, for the Bolshoi Ballet and for the Rembrandts and the Scythian gold at the Hermitage. We got a new impression of Siberia when, upon arrival at our vacation house on Moscow Road along the Russian River among the rolling hills of Sonoma County a few miles from the California coast, Vladik exclaimed, that this was just like home where he grew up in Siberia. We got a new impression of Moscow when we visited the home that he built in a small town near his institute for a marvelous dinner party with his wife Tiina and his research group. Our introduction to Mother Russia by her foremost scientific citizens has been very special for us.

There are these and so many more memories and reminders-Cuban cigars with which to bribe smoking colleagues; beautiful babushka dolls, folk art wood carvings, lovely water colors, a bound leather notebook. There were international conferences in Mègeve with post-deadline papers that provided a solid basis for understanding the mysterious IR multiple-photon dissociation of molecules, in Loen with its deep fjords, in the beautiful university town of Vilnius with its wonderfully vibrant and entrepreneurial people and its traditional sauna deep in the woods complete with birch branches, full repast, plus vodka and a swimming pond, both at ice temperature, in Honolulu with a post conference visit to a condo in Kawai including many trips by Vladik, our children and ourselves down a lava tube slide dropping into a water hole in the rain forest, in St. Petersburg, and elsewhere, each with exciting new science, culture, and both natural and man-made beauty.

And so, while we must say farewell to our friend, this wonderful citizen of the world, we will continue to benefit from his contributions and example far into the future.

Sincerely yours, Penny and Brad 